\title{
WAYANG BEBER REMENG MANGUNJAYA DI GELARAN, GUNUNGKIDUL DALAM KAJIAN HERMENEUTIKA
}

\author{
Yusuf Ahmadi \\ Pascasarjana, Universitas Negeri Yogyakarta \\ Email: yusuf.ahmadiii3@gmail.com
}

\begin{abstract}
Abstrak
Wayang Beber merupakan salah satu wayang tertua di Indonesia yang berasal dari pulau Jawa, dimana dalam penceritaan kisahnya dengan cara digelar atau di beberkan. Fungsi pertunjukan wayang beber meliputi fungsi ritual, fungsi sosial dan fungsi budaya. Wayang beber yang dipercaya keasliannya salah satunya berada di daerah Gunungkidul, yaitu di dusun Gelaran, Desa Bejiharjo, Kecamatan Karangmojo. Saat ini disimpan oleh Rubiyem selaku ahli waris dari benda cagar budaya tersebut. Wayang beber Gunungkidul menceritakan lakon Remeng Mangunjaya yang mengisahkan perjalanan cinta Raden Panji Asmarabangun dengan Dewi Galuh Candra Kirana. Lakon Remeng Mangunjaya berisi tentang ajaran tentang nilai-nilai kehidupan seperti ketulusan hati, keikhlasan, pengorbanan, ketekunan dan mengalahkan nafsu untuk menegakkan kebenaran. Makalah yang berjudul Kajian Hermeneutika Wayang Beber Remeng Mangunjaya D $i$ Dusun Gelaran, Desa Bejiharjo, Kecamatan Karangmojo, Kabupaten Gunungkidul ini bertujuan untuk mengenalkan kembali kebudayaan bangsa Indonesia kepada generasi saat ini agar dapat terus dilestarikan untuk generasi mendatang, serta untuk menjaga identitas bangsa agar tetap terjaga eksistensinya.
\end{abstract}

Kata kunci: wayang beber, Remeng Mangunjaya, hermenuitika

\section{WAYANG BEBER REMENG MANGUNJAYA IN GELARAN, GUNUNGKIDUL IN HERMENEUTICS STUDY}

\begin{abstract}
Wayang beber is one of the oldest puppets in Indonesia which comes from the island of Java, which is the telling of the story is being held or revealed. The functions of wayang beber performance include ritual function, social function, and cultural function. One of wayang beber that is believed to be original is in the region of Gunungkidul, namely in Gelaran Hamlet, Bejiharjo Village, Karangmojo Sub District. Currently, it is saved by Rubiyem as the heir of the object of cultural heritage. Gunungkidul wayang beber tells the story of Remeng Mangunjaya which tells the love journey of Raden Panji Asmarabangun with Dewi Galuh Candra Kirana. The story of Remeng Mangunjaya contains about teaching of the values of life such as integrity, sincerity, sacrifice, perseverance and defeating the lust to uphold the truth. This paper entitled Hermeneutics Study of Wayang Beber of Remeng Mangunjaya in Gelaran Hamlet, Bejiharjo Village, Karangmojo Sub District, Gunungkidul Regency aims to reintroduce Indonesian culture to the current generations so that it can continue to be preserved for future generations, as well as to maintain the nation's identity existence.
\end{abstract}

Keywords: wayang beber, Remeng Mangunjaya, hermeneutics 


\section{PENDAHULUAN}

Bangsa Indonesia merupakan bangsa yang dikenal menyimpan berjuta kekayaan alam didalamnya dan diakui di mata dunia sebagai bangsa yang memiliki keberagamaan seni dan budaya. Seni dan budaya bangsa ini merupakan karya para leluhur bangsa yang diwariskan secara turun-temurun sampai generasi saat ini. Setiap daerah tentunya membawa seni dan budayanya masing-masing yang menjadikan bangsa ini menjadi beragam, akan tetapi dari keberagaman tersebut menjelaskan bahwa bangsa Indonesia ini merupakan bangsa yang kaya dan dipersatukan atas nama perbedaan. Perkembangan zaman yang terus berlanjut dan sangat kompleks saat ini sangat berdampak pada dunia seni dan budaya, hal tersebut dipertegas dengan banyak ditemukannya generasi-generasi penerus yang lupa bahkan tidak mengenal seni dan budayanya sendiri. Akan tetapi banyak juga seni budaya yang masih eksis keberadaanya sampai saat ini salah satunya adalah wayang. Wayang merupakan seni pertunjukan warisan leluhur bangsa yang berasal dari pulau Jawa.

Wayang sudah dikenal masyarakat nusantara sejak zaman prasejarah. Kemudian pada saat masuknya pengaruh Hindu-Budha, cerita dalam wayang mulai mengadopsi kitab Mahabarata dari India. Lalu pada masa pengaruh Islam, wayang oleh para wali digunakan sebagai media dakwah yang tentunya dengan menyisipkan nilai-nilai ajaran Islam. Kata wayang dalam Kamus Besar Bahasa Indonesia, merupakan boneka tiruan orang yang terbuat dari pahatan kulit atau kayu dan sebagainya yang dapat dimanfaatkan untuk memerankan tokoh dalam pertunjukan drama tradisional (Jawa, Sunda, Bali), biasanya dimainkan oleh seseorang yang disebut dalang. Wayang dalam pengertian "hyang", "dewa", "roh", atau "sukma" memberikan gambaran bahwa wayang merupakan perkembangan dari upacara pemujaan roh nenek moyang bangsa Indonesia pada masa lampau. Wayang berasal dari kata wewayangan atau wayangan, yang berarti bayangan. Arti harfiah dari pertunjukkan wayang adalah pertunjukkan bayang-bayang. Arti filsafat yang lebih dalam lagi adalah bayangan kehidupan manusia atau angan-angan manusia tentang kehidupan manusia di masa lalu itu adalah ceritera tentang kehidupan nenek moyang. Pada dasarnya pertunjukkan wayang pada masa lalu adalah sebagai upacara ritual pemujaan roh nenek moyang, setelah masuknya ajaran agama Islam pagelaran wayang khususnya bagi masyarakat Jawa merupakan sarana untuk hiburan yang sekaligus didalamnya tersirat ajaran-ajaran tentang kehidupan dunia dan akhirat. Setiap lakon-lakon yang dibawakan oleh sang dalang tentunya membawa maksud dan tujuannya sendiri-sendiri yang dapat diambil hikmahnya, hal tersebutmenjelaskan bahwa setiap pagelaran wayang kulit merupakan tontonan sekaligus tuntunan bagi masyarakat secara luas. Dengan begitu Wayang juga tersmasuk sebagai seni rakyat, hal tersebut dipertegas oleh perntayaan Sutiyono dalam jurnal Imaji, menyatakan bahwa Semula kehadiran seni rakyat berfungsi untuk kemuliaan hidup manusia dalam bentuk memberikan keseimbangan kosmos.

Terdapat banyak jenis-jenis wayang yang berasal dari pulau Jawa, seperti Wayang Kulit yaitu jenis wayang yang terbuat dari pahatan kulit sapi atau kerbau, sampai saat ini masih sering kita temukan pagelarannya, akan tetapi terdapat jenis wayang yang lebih tua usianya dari wayang kulit yaitu wayang beber. Wayang Beber adalah seni wayang yang muncul dan berkembang di Jawa pada masa pra Islam dan masih berkembang di daerah-daerah tertentu di Pulau Jawa. Dinamakan wayang Beber karena berupa lembaran lembaran (beberan) yang dibentuk menjadi tokoh tokoh dalam cerita wayang seperti Mahabharata maupun Ramayana. Jenis pertunjukkan wayang dengan gambar-gambar sebagai objek pertunjukkan. Gambar-gambar tersebut dilukiskan pada selembar kertas atau kain, gambar dibuat dari satu adegan menyusul dengan adegan lain dan diceritakan satu demi satu oleh Dalang. Gambar-gambar tersebut dipertunjukkan dengan cara membentangkan (membeber) gulungan. Gambar-gambar tersebut dilukiskan pada selembar kertas atau kain, gambar dibuat 
dari satu adegan menyusul dengan adegan lain dan diceritakan satu demi satu oleh dalang.

Salah satu wayang beber yang usianya sudah tergolong tua adalah Wayang Beber Remeng Mangunjaya yang sampai saat ini keasliannya masih tersimpan di Dusun Gelaran, Desa Bejiharjo, Kecamatan Karangmojo, Kabupaten Gunungkidul. Lakon Remeng Mangunjaya menurut R.M. Sayid selesai dibuat pada masa pemerintahan Sunan Pakubuwono II (1660). Wayang Beber Gunungkidul Remeng Mangunjaya juga berkaitan erat dengan ritual, sehingga gulungan wayang beber tidak bisa dibuka sembarangan setiap saat karena dianggap sakral, gulungan hanya dibuka pada waktu tertentu saja, kecuali dengan syarat "sajen" dan "uborampe among-among". Saat mementaskan pertunjukan wayang beber, dalang duduk di depan layar dan dengan menggunakan tuding (stik panjang) melakonkan cerita sambil menunjuk gambar-gambar yang dikisahkan.

Di Indonesia wayang beber asli yang masih terbuat dari daluwang (kertas jawa) dipercaya hanya terdapat di Gunungidul dan Pacitan. Namun keduanya sudah dalam keadaan yang memprihatinkan. Untuk Wayang Beber Remeng Mangunjaya sekarang ini dimiliki oleh ibu Rubiyem dan anaknya yang bernama Wisto Utomo. Mereka merupakan keturunan generasi kelimabelas dari pemilik wayang beber tersebut. Meskipun telah ada beberapa upaya yang dilakukan pemilik wayang dan beberapa pihak yang peduli terhadap Wayang Beber tersebut. Namun upaya untuk pelestarian wayang ini memang perlu dilakukan secara terus menerus. Hal ini sebetulnya untuk menjaga agar Wayang Beber tetap lestari dan bisa dinikmati oleh generasi yang akan datang. Beberapa upaya yang telah dilakukan adalah dengan melakukan duplikasi empat gulungan utuh dari Wayang Beber Remeng Mangunjaya, duplikasi kotak penyimpanan yang berfungsi juga sebagai sarana untuk pagelaran Wayang Beber, pembuatan buku pedoman dalang, dan juga regenerasi dalang Wayang Beber lakon Remeng Mangunjaya. Meskipun telah dilakukan berbagai macam upaya terhadap pelestarian maupun pengembangan terhadap wayang ini, tetap saja masih banyak yang belum mengetahui perihal Wayang Beber.

Meskipun demikian pelestarian dengan pengenalan serta pengembangan wayang beber ini memang harus dilakukan secara terus menerus. Sehingga memang perlu adanya peran serta berbagai pihak yang peduli agar upayaupaya tersebut bisa dilakukan dan berjalan dengan baik. Jadi peranan media-media komunikasiyangbisa dipakaiuntukmewartakan hal-hal yang telah disampaikan diatas menjadi sangat dibutuhkan, hal ini agar perkembangan terbaru dari Wayang Beber Remeng Mangunjaya bisa tersampaikan dengan baik kepada masyarakat luas. Berdasarkan uraianuraian diatas maka penulis terdorong untuk mengkaji lebih dalam lagi mengenai wayang beber, Remeng Mangunjaya di Dusun Gelaran, Desa Bejiharjo, Karangmojo, Gunungkidul dengan pendekatan Hermeneutika, mulai dari sejarah sampai pemaknaan wayang beber Remeng Mangunjaya.

\section{KAJIAN TEORITIK}

\section{Hermeneutika}

Secara etimologi, kata hermeneutik berasal dari bahasa Yunani hermeneuein yang berarti menafsirkan. Maka kata benda heremenia secara harfia dapat diartikan sebagai penafsiran atau interpretasi. Istilah ini diambil dari mitologi Yunani pada tokoh yang bernama Hermes, yaitu seorang utusan yang mempunyai tugas menyampaikan pesan Jupiter kepada manusia. Hermes digambarkan sebagai seorang yang mempunyai kaki bersayap, dan lebih banyak dikenal dengan sebutan Mercurius dalam bahasa latin. Tugas Hermes adalah menerjemahkan pesan-pesan dari dewa di Gunung Olympus ke dalam bahasa yang dapat dimengerti oleh umat manusia. Oleh karena itu fungsi hermes adalah penting sebab bila terjadi kesalahpahaman tentang pesan dewa-dewa, akibatnya akan fatal bagi seluruh umat manusia. Hermes harus mampu menginterpretasikan atau menyadur sebuah pesan yang dipergunakan oleh pendengarnya. Oleh karena itu hermeneutika pada akhirnya diartikan sebagai "proses mengubah sesuatu 
atau situasi ketidak tahuan menjadi mengerti" (Palmer, 1969:3).

Menurut Sumaryono

(1999:20), menjelaskan bahwa secara etimologis, kata "hermeneutic" berasal dari bahasa Yunani hermeneuein yang berarti "menafsirkan", dan dari kata hermeneuin ini dapat ditarik kata benda hermeneia yang berarti "penafsiran" atau "interpretasi" dan kata hermeneutes yang berarti interpreter (penafsir). Hal tersebut diperjelas oleh pendapat Schleiermacher (1768-1834), ada dua tugas hermeneutik yang pada hakikatnya identik satu sama lain, yaitu interpreasi gramatikal dan interpretasi psikologis. Bahasa gramatikal merupakan syarat berpikir setiap orang.

Terdapat banyak sekali tokoh-tokoh filsuf dengan pendekatan Hermeneutika-nya, akan tetapi dalam pembahasan ini penulis menggunakan pendekatan Hermeneutika dari Hans-Georg Gadamer. Dasar dari hermeneutika Gadamer adalah sebuah logika klasik, bahwa orang bisa memahami keseluruhan dengan terlebih dahulu memahami bagianbagiannya. Hal yang sama dapat diterapkan untuk memahami suatu teks. Maksud utama dari keseluruhan teks dapat dipahami dengan berpusat pada bagian-bagian teks tersebut, dan sebaliknya bagian-bagian teks itu dapat dipahami dengan memahami keseluruhan teks. Pengandaian hermeneutika Gadamer adalah, bahwa keseluruhan (whole) dan bagian (parts) selalu koheren. Supaya dapat memperoleh pemahaman yang tepat, si pembaca teks haruslah memahami koherensi antara makna keseluruhan dan makna bagian dari teks tersebut.

Dalam pandangan Gadamer, "understanding is always an historical, dialectical, linguistic event-in the sciences, in the humanities. Hermeneutic is the ontology and the phenomenology of understanding. The key to understanding are not manipulation and control but participation and openness, not knowledge but experience, not methodology but dialectic (Palmer, 1969: 215). Dengan demikian ada tiga hal yang menurutnya terkait erat dengan pemahaman yaitu historis, dialektik dan linguistic. Jadi dapat disimpulkan bahwa hermenutika Gadamer mengungkap pemahaman dari sesuatu dengan mengkaji sejarah, proses penciptaan sesuatu dan pemaknaan secara keseluruhan. Namun dalam pembahasan kali ini penulis membatasi hanya pada sejarah dan pemaknaan wayang beber Remeng Mangunjaya di Dusun Gelaran, Bejiharjo, Karangmojo, Gunungkidul.

\section{Wayang Beber}

Wayang Beber adalah seni wayang yang muncul dan berkembang di Jawa pada masa pra Islam dan masih berkembang di daerah daerah tertentu di Pulau Jawa. Dinamakan wayang beber karena berupa lembaran lembaran (beberan) yang dibentuk menjadi tokoh tokoh dalam cerita wayang baik Mahabharata maupun Ramayana. Wayang beber muncul dan berkembang di Pulau Jawa pada masa kerajaan Majapahit. Gambar-gambar tokoh pewayangan dilukiskan pada selembar kain atau kertas, kemudian disusun adegan demi adegan berurutan sesuai dengan urutan cerita. Konon oleh para Wali di antaranya adalah Sunan Kalijaga wayang beber ini dimodifikasi bentuk menjadi wayang kulit dengan bentuk bentuk yang bersifat ornamen yang dikenal sekarang, karena ajaran Islam mengharamkan bentuk gambar makhluk hidup (manusia, hewan) maupun patung serta menambahkan Pusaka Hyang Kalimusada. Wayang hasil modifikasi para wali inilah yang digunakan untuk menyebarkan ajaran Islam dan yang kita kenal sekarang. Menurut Kitab Sastro Mirudo, Wayang Beber dibuat pada tahun 1283, dengan Condro Sengkolo, Gunaning Bujonggo Nembah Ing Dewo (1283), Kemudian dilanjutkan oleh Putra Prabu Bhre Wijaya, Raden Sungging Prabangkara, dalam pembuatan wayang beber. Wayang Beber juga memuat banyak cerita Panji, yakni Kisah Cinta Panji Asmoro Bangun yang merajut cintanya dengan Dewi Sekartaji Putri Jenggolo/ Dewi Galuh Candra Kirana.

Wayang Beber hanya dipentaskan untuk upacara ruwatan atau nadar saja. Wayang ini berbentuk lukisan di atas kertas, dengan roman sepertiwayangkulitpurwahanyakedua matanya 
nampak. Sikap wayang bermacam-macam, ada yang duduk bersila, sedang berjalan, sedang berperang dan sebagainya. Sebelum melakukan pagelaran Wayang Beber, harus dilakukan semacam ritual untuk menghormati leluhur. Ritual itu berupa pembakaran dupa dengan adanya persembahan atau sesajen. Ritual pembakaran dupa tersebut sambil diringi oleh doa yang dilakukan oleh dalang, baru kemudian Wayang Beber dapat dimainkan dengan cara dibuka satu pesatu atau digelar/dibeber. Satu gulungan berisi 4 adegan, sehingga ketika adegan pertama diperlihatkan maka adegan ketiga sampai keempat masih dalam posisi tergulung. Kemudian jika berpindah dari gulungan satu kegulungan selanjutnya, maka pasak di sebelah kanan dalang dilepas terlebih dahulu, kemudian pasak gulungan yang baru dipasang, selanjutnya membuka gulungan baru sambil menutup gulungan sebelumnya, dan terakhir memasang pasak pada tempat penyimpanan Wayang Beber tersebut. Dalang menceritakan cerita yang terlukis di gulungan Wayang Beber tersebut dengan menggunakan Bahasa Jawa dengan posisi membelakangi Wayang Beber, atau menghadap penonton. Dan untuk menutup pagelaran Wayang Beber ini, dalang mematikan dupa sambil membaca doa.

\section{PEMBAHASAN}

1. Sejarah Singkat Wayang Beber Remeng Mangunjaya di Dusun Gelaran, Desa Bejiharjo, Kecamatan Karangmojo, Kabupaten Gunungkidul

Pada umumnya pertunjukan wayang menggunakan boneka sebagai wujud dari tokoh. Boneka-boneka dalam wayang bisa berbentuk dua dimensi seperti wayang kulit purwa atau wayang berbentuk tiga dimensi seperti wayang golek. Salah satu bentuk wayang yang tidak berwujud boneka adalah wayang beber. Wayang beber mewujudkan tokoh-tokohnya dengan cara dilukis pada selembar kertas dua dimensi. Lembaran kertas tersebut melukiskan peristiwa yang terjadi dalam lakon yang dimainkan. Pertunjukan wayang beber dimainkan oleh seorang dalang yang membentangkan lembaran kertas. Dalang mengisahkan peristiwa demi peristiwa sesuai gambar yang disajikan. Adegan-adegan yang telah selesai dituturkan digulung kembali dan dalang membentangkan gulungan yang baru. Gaya pertunjukan wayang beber tidak berbeda jauh dengan wayang kulit purwa. Dalang melakukan pencandraan atau penuturan cerita pada bagian pra adegan, di tengah-tengah adegan, dan setelah adegan usai. Cerita dituturkan dalam bentuk prosa bebas atau dilagukan. Penuturan cerita dalam bentuk prosa bebas terdiri dari kandha dan janturan. Sedangkan narasi yang dilagukan biasa disebut sulukan. Pada awal kemunculannya, wayang beber merupakan pertunjukan yang bersifat ritual. Sebagaimana pertunjukan ritual, wayang beber digelar dalam konteks upacara tertentu di mana pertunjukan menjadi media yang menautkan antara yang profan dan yang transendental. Dunia profan berhubungan dengan fungsi-fungsi sosial dan hiburan bagi masyarakat. Dunia transendental berhubungan dengan hal-hal spiritual yang mengubungkan dunia mikrokosmos dan makrokosmos. Di mana manusia berada dalam sistem yang dipengaruhi oleh kekuatan-kekuatan di luar dirinya.

Wayang beber sebagai sebuah pertunjukan memiliki dua makna penting, yaitu sebagai tontonan sekaligus sebagai tuntunan. Bahwa lakon yang dibeberkan merupakan kehidupan yang memiliki nilai-nilai untuk dijadikan tuntunan. Masyarakat membutuhkan tuntunan agar terjadi keseimbangan dalam hidup. Keseimbangan dalam kehidupan termasuk keseimbangandalammasyarakat dan kehidupan bernegara pada waktu itu. Pertunjukan wayang beber diduga telah ada sejak zaman Majapahit kurang lebih 1361. Wayang beber pada masa itu merupakan pusaka kerajaan. Wayang beber dianggap sebagai pusaka karena pertunjukan wayang beber pada masa menjadi memiliki fungsi ritual. Di mana wayang beber tidak sekedar sebuah tontonan tetapi menjadi sarana yang menghubungkan antara manusia dengan kekuatan-kekuatan di luar diri manusia yang berpengaruh terhadap keseimbangan kehidupan. Wayang beber menjadi bagian 
ritual daur hidup masyarakat Jawa. Pada masa itu wayang beber masih dilukis hitam putih. Medianya berupa kertas yang digulung dan dibentangkan (dibeber) ketika dimainkan. Pertunjukan wayang beber dipentaskan secara utuh dengan iringan gamelan lengkap. Dalang wayang beber membentangkan kertas sambil menceritakan adegan-adegan yang terdapat dalam gambar tersebut. Kebenaran bahwa wayang beber telah ada sejak zaman Majapahit didukung oleh cerita yang dituturkan seorang Cina yang bernama Ma Huan. Ma Huan merupakan salah satu rombongan Ceng Ho yang waktu itu berkunjung ke Majapahit. Kesaksian Ma Huan menunjukkan bahwa penonton kala itu mengikuti jalannya pertunjukan dengan antusias. Para penonton mengikuti tuturan dalang yang mengisahkan peristiwa demi peristiwa berdasarkan pembabakan yang tertuang dalam gambar. Pada zaman Majapahit wayang beber belum memainkan lakon Panji. Pada masa itu wayang beber memainkan lakon yang bersumber dari Mahabharata dan Ramayana. Hal ini menunjukkan bahwa Mahabharata dan Ramayana menjadi sumber lakon-lakon untuk pertunjukan. Mahabharata dan Ramayana yang berasal dari India telah menjadi bagian penting dalam kehidupan masyarakat Jawa.

Catatan sejarah tidak menyebutkan bagian-bagian cerita dalam Mahabharata dan Ramayana yang dijadikan sumber lakon. Wayang beber mulai mengambil lakon yang bersumber dari Cerita Panji setelah zaman Majapahit, karena pada zaman Majapahit belum dikenal Cerita Panji. Menurut Poerbatjaroko, Cerita Panji tercipta pada atau sesudah masa kejayaan Majapahit (1293-1520). Menurut Ras, sebagaimana dikutip Sayuti (1999:186), cerita Panji menceritakan satu episode dalam sejarah legendaris Jawa. Oleh karena itu, cerita Panji dapat dijumpai dalam Babad Tanah Jawi, Serat Kanda, cerita Jaya Lengkara, dan Babad Daha- Kediri. Perang antara kerajaan Majapahit dan kerajaan Demak yang pada akhirnya dimenangkan Demak mengakibatkan wayang beber berpindah tangan. Pusaka kerajaan Majapahit diboyong ke Demak. Salah satu pusaka yang diboyong ke Demak adalah tiga perangkat wayang beber. Wayang beber dipilih diboyong karena alasan kepraktisan. Wayang beber dapat digulung dan mudah dibawa. Sumber sejarah tidak menyebutkan wayang kulit purwa turut diangkut dalam peristiwa tersebut. Pada sekitar 1378 gambar wayang beber tidak lagi hitam putih. Wayang beber digambar dengan berbagai perpaduan warna sehingga lebih menarik. Tabrani mencatat bahwa pada 1397 tokoh-tokoh dalam wayang beber yang semula digambar tampak muka, mulai digambar tampak samping. Hal ini diduga mengikuti perubahan pada relifrelief candi. Pada 1521 bentuk figur tokohtokoh dalam wayang beber mendapat sentuhan dengan stilisasi bentuk. Puncak popularitas wayang beber diperkirakan pada 1562 . Setelah tahun itu, wayang beber mulai kurang populer karena wayang kulit purwa dipandang lebih menarik. Tokoh-tokoh dalam wayang dibuat boneka sehingga dapat dimainkan sesuai karakter tokoh.

Wayang beber dapat digolongkan sebagai jenis wayang yang usianya telah tua dan kini tidak lagi digemari oleh masyarakat secara luas. Wayang beber peninggalan masa lalu yang kini tersisa adalah wayang beber yang ditemukan di desa Karangtalun, Kelurahan Kedompol, Kecamatan Donorejo, Kabupaten Pacitan. Oleh karena ditemukan di Pacitan, maka wayang beber tersebut dinamakan wayang beber Pacitan. Wayang beber Pacitan melukiskan cerita Panji Asmarabangun dan Dewi Sekartaji. Lakon yang dimainkan tepatnya berjudul Jaka Kembang Kuning. Wayang ini berjumlah 6 gulungan dan masing-masing gulungan memuat 4 adegan sehingga jumlah adegan ada 24 . Konon adegan yang ke 24 tidak boleh dibuka (Haryono, 2009:8). Wayang beber juga ditemukan di daerah Gunungkidul, yaitu di Dusun Gelaran, Desa Bejiharjo, Kecamatan Karangmojo. Rubiyem adalah penyimpan sekaligus ahli waris seperangkat kesenian kuno berupa ampok atau kotak berisi gulungan kain bergambar yang lebih populer disebut wayang beber, Ia mengaku sebagai pewaris generasi ke-15 dari benda yang termasuk dalam 
kategori benda cagar budaya tersebut. Rubiyem menjelaskan bahwa sebelum warisan tersebut sampai kepadanya secara turun temurun, ia dan pendahulunya hanya mampu mengingat 9 nama keturunan termasuk dirinya. Nama-nama itu adalah Ki Guno Perwito, Guno Setiko, Guno Kromo, Guno Reso, Guno Karyo, Wono Dikromo, Kromo Sentono, Sapartono, baru kemudian Rubiyem. Wayang beber warisan kakeknya tersebut bernama Wayang Beber Kyai Remeng Mangunjaya. Dalam satu kotak terdapat delapan gulungan. Empat gulungan berisi cerita perjalanan cinta Panji Asmara Bangun dan Galuh Candrakirana yang berasal dari kisah Babad Kediri.

Awal kehadirannya di Gunungkidul, Wayang Beber dengan lakon Remeng Mangunjaya dibawa oleh Pangeran Kajoran yang kemudian diselamatkan oleh $\mathrm{Ki}$ Cremoguno. Sebelumnya wayang bebertersebut milik Keraton Kasunanan Surakarta. Kurun waktu 1740-1743 diprediksi menjadi awal mula kehadirannya di Gunungkidul.Wayang beber di Gunungkidul memainkan lakon Kyai Remeng atau Remeng Mangunjaya, oleh karena itu dinamakan wayang beber Kyai Remeng Mangunjaya. Wayang beber Kyai Remeng Mangunjaya terdiri dari 8 gulungan; ada yang memuat cerita Jaka Tarub, cerita Syech Bakir, cerita peperangan antara Resi Puyung Aking melawan Kyai Remeng (Haryono, 2009:8). Mangkunegara VII dari Surakarta pernah berniat membeli perangkat wayang beber dari pemiliknya, tetapi tidak diperbolehkan. Alasannya wayang beber tersebut merupakan pusaka yang diwariskan secara turun temurun. Oleh karena itu, Mangkunegara VII memerintahkan untuk membuat duplikasi wayang beber Jaka Kembang Kuning pada tahun 1939. Kemudian dilanjutkan dengan membuat duplikasi Remeng Mangunjaya pada tahun 1941.

\section{Makna Wayang Beber Lakon Remeng Mangunjaya di Dusun Gelaran, Desa Bejiharjo, Kecamatan Karangmojo, Kabupaten Gunungkidul}

Wayang Beber lakon Remeng Mangunjaya di Dusun Gelaran, Desa Bejiharjo, Kecamatan Karangmojo, Kabupaten Gunungkidul total memiliki empat gulungan dan setiap gulungan dibagi menjadi empat adegan atau pejagong. Sehingga total terdapat 16 adegan dalam empat babak atau gulungan. Adapun tokohtokoh dalam cerita Remeng Mangunjaya adalah sebagai berikut: 1. Raden Panji Asmarabangum merupakan tokoh utama dalam lakon ini yang juga berperan sebagai Kyai Remeng Mangunjaya, 2. Dewi Galuh Candrakirana merupakan istri dari Raden Panji Asmarabangun, putri dari Raja Kediri, 3. Bancak Enggel dan Bancak Doyok keduanya merupakan abdi setia dari Raden Panji Asmarabangun, 4. Raja Kediri adalah ayahanda dari Dewi Galuh Candrakirana, 5. Prabu Klanasewandana yang merupakan musuh dari Raja Kediri yang cintanya ditolak oleh Dewi Galuh Candrakirana, 6. Patih Gajah Gurita 7. Resi Puyangaking seorang resi yang menjadi kepercayaan dari Prabu Klanasewandana. Adapun intisari cerita dari Wayang Beber Gunungkidul lakon Remeng Mangunjaya adalah sebagai berikut:

Diceritakan bahwa terdapat suatu kerajaan yang bernama Jenggala, raja dari kerajaan tersebut bernama Raden Panji Asmarabangun. Pada suatu ketika Raden Panji Asmara Bangun sedang duduk bercengkerama bersama dengan istrinya yang bernama Dewi Galuh Candra Kirana, saat itu Raden Panji bertanya kepada istrinya "Wahai istriku seperti apa cintamu kepadaku?" Dewi Galuh Candra Kirana pun menjawab "Suamiku, cintaku kepadamu adalah seperti kuku yang menempel pada jari, karena bagaimanapun juga ketika kuku tersebut dipotong beberapa kali, selama manusia itu masih hidup maka kuku tersebut tetap akan terus tumbuh, sama seperti cintaku kangmas". Jawaban Dewi Galuh Candra Kirana yang penuh dengan filsafat tersebut menyadarkan Raden Panji bahwa istrinya memiliki ilmu 
tentang kehidupan yang lebih tinggi dari pada dirinya. Hal tersebut menyebabkan Raden Panji pergi meninggalkan Jenggala tanpa pamit kepada istrinya, untuk bertapa mencari ilmu tentang filsafat kehidupan yang lebih tinggi dari istrinya Dewi Galuh Candra Kirana. Meskipun sudah dilarang oleh abdi setianya yaitu Bancak Enggel dan Bancak Doyok, Raden Panji tetap pergi meninggalkan istana.

Di Kerajaan Bantar Angin Prabu Klanasewanda sedang mengadakan pertemuan agung, pertemuan tersebut dihadiri oleh Patih Gajah Gurita, Resi Puyangaking dan para pejabat istana lainnya. Dalam pertemuan itu membahas tentang kabar bahwa Dewi Galuh Candra Kirana menjadi seorang janda karena ditinggal pergi oleh Prabu Panji Asmarabangun dan pulang kepada ayahnya di Kediri. Tersiar kabar pula bahwa saat ini Raja Kediri sedang mengadakan sayembara meniti titian tali rotan di Seminang untuk menemukan suami baru bagi putrinya. Prabu Klanasewandana ingin mempersunting Dewi Galuh Candra Kirana menjadi istrinya namun Ia juga merasa bahwa Raden Panji pasti juga akan datang untuk mendapatkan istrinya kembali. Oleh karena itu Prabu Klanasewandana mengutus Resi Puyangaking untuk mencari dan membunuh Raden Panji agar keinginannya untuk mempersunting Dewi Galuh Candra Kirana dapat tercapai.

Raden Panji Asmarabangun yang sudah menjalani tapa telah mendapatkan ilmu tentang kehidupan yang sangat tinggi dan Ia pun mengubah namanya menjadi Remeng Mangunjaya. Pada suatu hari Remeng Mangunjaya kedatangan Dewa dari kayangan yang menceritakan tentang adanya sayembara meniti titian tali rotan yang diadakan oleh raja kediri di Seminang untuk mencari pengganti suami putrinya. Dewa menyarankan agar Remeng Mangunjaya mengikuti sayembara tersebut untuk mendapatkan Dewi Candra Kirana kembali. Akhirnya Remeng Mangunjaya datang ke seminang dan dapat memenangkan sayembara serta mendapatkan istrinya kembali. Namun keberhasilan itu menjadikan Prabu Klanasewandana yang merupakan musuh dari Remeng Mangunjaya kecewa. Prabu Klanasewandana beserta pasukannya menyerang Kediri. Meskipun Ia dibantu oleh orang-orang sakti seperti Resi Puyangaking, Patih Gajah Gurito dengan ajian Wewe Putihnya, mereka tetap bisa ditumpas oleh Raja Kediri, Remeng Mangunjaya dan para sekutunya. Prabu Klanasewandana melarikan diri ke kerajaannya, sedang patih Gajah Gurito dan Wewe Putihnya tewas di medan pertempuran. Setelah kemenangan itu, Raden Panji Asmarabangun atau Remeng Mangunjaya akhirnya membawa kembali istrinya untuk pulang ke Jenggala.

Uraian diatas merupakan intisari cerita wayang beber Gunungkidul dengan lakon Remeng Mangunjaya. Dari lakon Remeng Mangunjaya dapat kita maknai bahwa lakon tersebut ingin mengungkapkan ajaran tentang nilai-nilai kehidupan, seperti ketulusan cinta yang digambarkan melalui tokoh Dewi Galuh Candra Kirana, Ia menjelaskan ketulusan cintanya kepada Raden Panji Asmarabangun bahwa cintanya ibarat kuku, yang akan terus tumbuh meskipun telah di potong berkalikali. Hal tersebut menegaskan bahwa cinta yang dilandasi dengan ketulusan akan tetap tumbuh meskipun harus melewati rintanganrintangan di dalam kehidupan rumah tangga. Ajaran tentang nilai-nilai kehidupan yang lain digambarkan oleh Raden Panji Asmarabangun atau Kyai Remeng Mangunjaya untuk mendapatkan ilmu tentang kehidupan yang lebih tinggi, ia rela mengorbankan meninggalkan istri dan kerajaannya dan melakukan tapa yang entah berapa tahun lamanya. Hal tersebut menegaskan bahwa lakon ini ingin mengajarkan keteguhan hati dan keikhlasan untuk mencari serta mendapatkan ilmu meskipun harus mengorbankan harta, benda bahkan nyawa sekalipun. Terdapat juga nilai-nilai kehidupan untuk melawan kejahatan dan nafsu yang berperan sebagai penyeimbang dari kebenaran. Hal tersebut digambarkan oleh tokoh Prabu Klanasewandana yang tidak terima atas kekalahannya dalam sayembara yang diadakan oleh Raja Kediri dan gagal memperistri Dewi Galuh Candra Kirana, 
akhirnya Ia menyerang Kerajaan Kediri dengan membawa bala pasukannya. Namun pada akhirnya kebenaranlah yang akan mengalahkan kejahatan angkara murka.

\section{KESIMPULAN}

Wayang Beber merupakan salah satu wayang tertua di Indonesia, di mana dalam penceritaan kisahnya dengan cara digelar atau di beberkan. Fungsi pertunjukan wayang Beber meliputi fungsi ritual, fungsi sosial dan fungsi budaya. Pada zaman dahulu sebelum dibuat dalam bentuk satauan dalam bentuk pahatan pada kayu dan kulit, wayang telah diukir pada wahana batu. Ukiran-ukiran tersebut dinamakan dengan relief yang banyak menghiasi candi-candi di Jawa. Ukiran pada batu itulah yang kemudian menjadi cikal bakal wayang Beber. Wayang beber juga ditemukan di daerah Gunungkidul, yaitu di dusun Gelaran, Desa Bejiharjo, Kecamatan Karangmojo. Nama pemiliknya saat ini adalah Rubiyem Ia adalah ahli waris seperangkat kesenian kuno yang berupa ampok atau kotak berisi gulungan Wayang Beber. Keseluruhannya Rubiyem menyimpan empat gulungan dan setiap gulungan dibagi menjadi empat adegan atau pejagong. Sehingga total terdapat 16 adegan dalam empat babak atau gulungan. Wayang Beber tersebut menceritakan tentang lakon Remeng Mangunjaya.

Wayang Beber dengan lakon Remeng Mangunjaya dapat kita maknai bahwa lakon tersebut ingin mengungkapkan ajaran tentang nilai-nilai kehidupan, seperti ketulusan hati untuk mencintai pasangan yang digambarkan melalui tokoh Dewi Galuh Candra Kirana, mengajarkan pengorbanan dan kesungguhan hati dalam mencari ilmu yang digambarkan oleh Raden Panji Asmarabangun atau Remeng Mangunjaya, serta ajaran untuk menjaga nafsu dan melawan kejahatan yang digambarkan oleh Remeng Mangunjaya melawan Prabu Klanasewandana. Secara keseluruhan penulisan makalah yang berjudul Kajian Hermeneutika Wayang Beber Remeng Mangunjaya Di Dusun Gelaran, Desa Bejiharjo, Kecamatan Karangmojo, Kabupaten
Gunungkidul ini bertujuan untuk mengenalkan kembali kebudayaan bangsa Indonesia kepada generasi saat ini dan dapat terus dilestarikan untuk generasi mendatang, agar yang menjadi identitas dari bangsa ini tetap terjaga yaitu kekuatan kebudayaan lokalnya.

\section{DAFTAR PUSTAKA}

\section{Buku:}

E. Sumaryono,. 1999. Hermeneutika: Sebuah Metode Filsafat, Yogyakarta: Kanisius.

Gadamer, Hans-Georg, 2004. Kebenaran dan Metode, terj. Ahmad Sahidah, Jogjakarta: Pustaka Pelajar, 2004

Palmer, E.Richard, Hermeneutics Interpretation Theory in Schleiermacher, Dilthey, Heidegger, and Gadamer, Evanston: Northwestern University Press, 1969

Suharyono, Bagyo. 2005. Wayang Beber Wonosari. Wonogiri: Bina Citra Pustaka

Tabrani, Primadi. 1982. "Meninjau Tata Ungkapan Bahasa Rupa dari Wayang Beber, sebuah Media Rupa Tradisional yang Langka, dari Telaah Tata Ungkapan Bahasa Rupa Media Rupa Rungu Modern".

\section{Sumber Internet:}

Sejarah Wayang Beber (2011) (http:// jogjanews.com/sejarah-wayang-beberdigunakanuntuk-menaklukan-musuh, diakses 24 Desember 2019)

The Metamorphosis of Wayang Beber (2013) (http://www.thejakartapost.com/ news/2013/04/19/the-metamorphosiswayangbeber.html, diakses 25 Desember 2019)

Wayang Beber (2012) (http://sosbud. kompasiana.com/2012/10/24/wayangbeber-yang-mudayang-melestarikanbudaya-498124.html, diakses 20 Desember 2019)

\section{Artikel/ Jurnal:}

Femi Eka- Revitalisasi Cerita Panji Dalam Wayang Beber - Jurnal Studi Budaya Nusantara - 2018 
Graham McCaffrey, RN, PhD- Hermeneutics as Research Approach: A Reappraisal. International Journal of Qualitative Methods- 2012

Indiria Maharsi - Penciptaan Ilustrasi Buku "Wayang Beber Wonosari"- Jurnal DEKAVE- 2018

\section{DAFTAR LAMPIRAN}

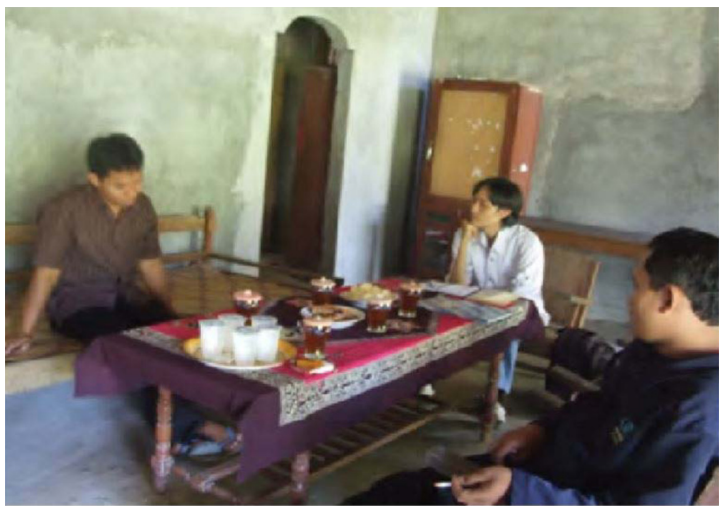

(Wawancara dengan pewaris Wayang Beber Gunungkidul

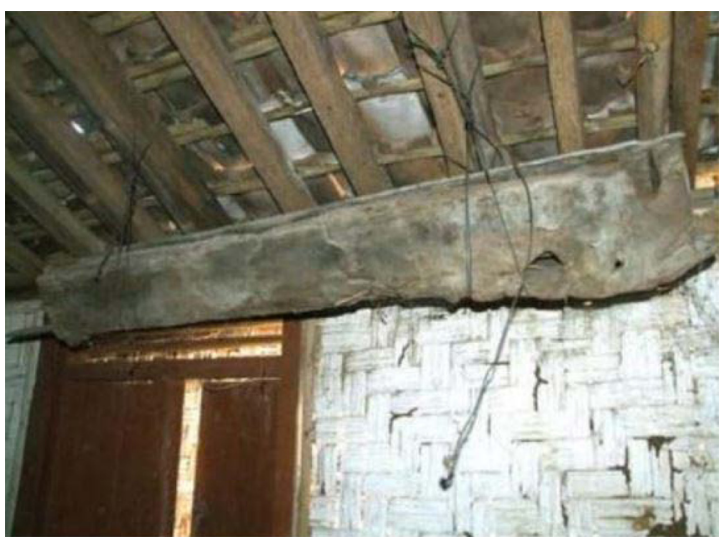

Kotak/Peti penyimpanan Wayang Beber Gunungkidul
I Wayan Suardana - Merajut Rupa Tradisional Dalam Pengembangan Seni Rupa Kontemporer Indonesia - JURNAL SEMBADA- 2013

Sutiyono - Seni Rakyat dalam Dimensi Industrial - Jurnal Imaji -

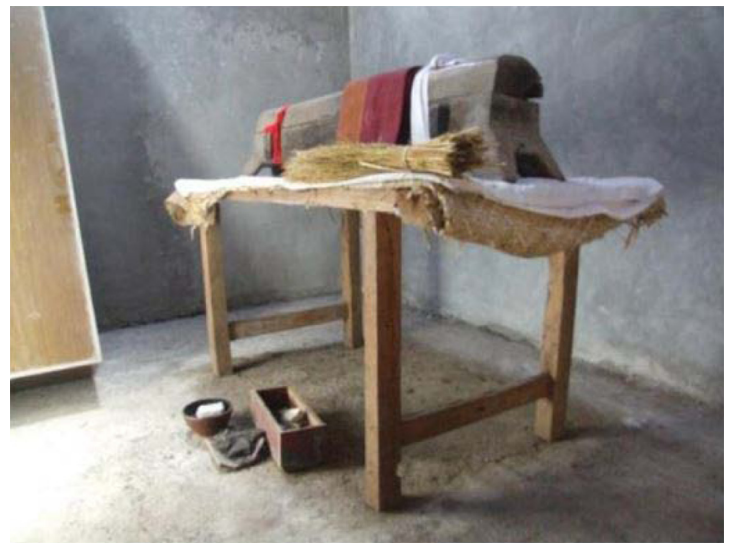

Kotak/Peti penyimpanan Wayang Beber Gunungkidul

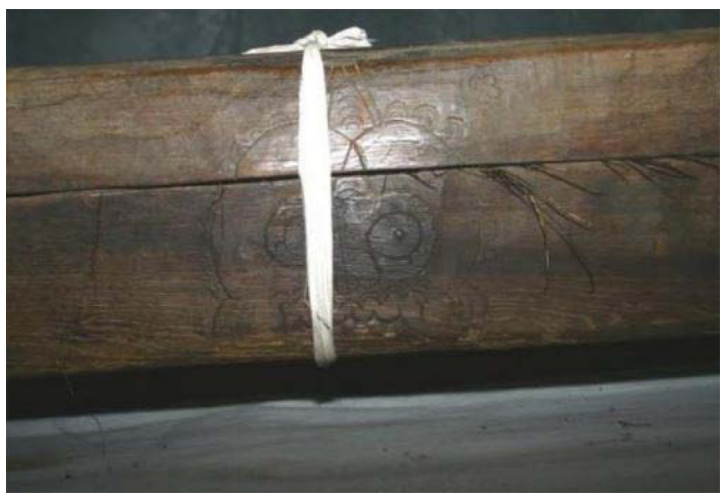

Ukiran Banaspati pada peti penyimpanan Wayang Beber 


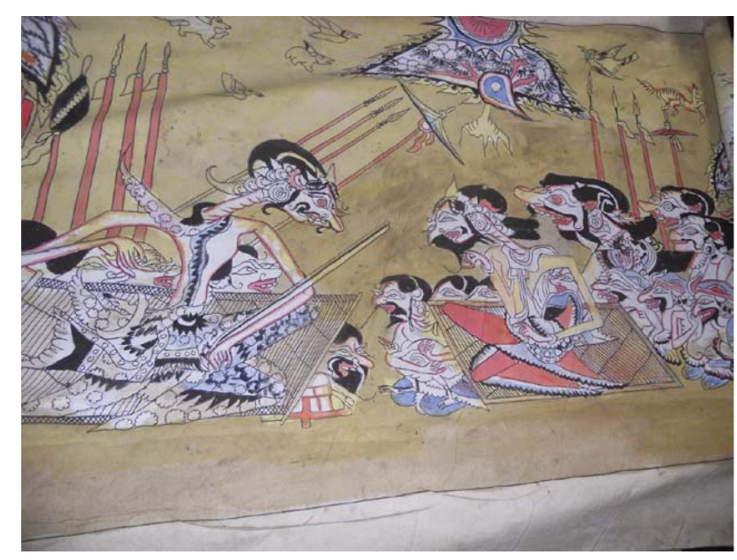

Duplikasi Wayang Beber Remeng Mangunjaya Gunungkidul

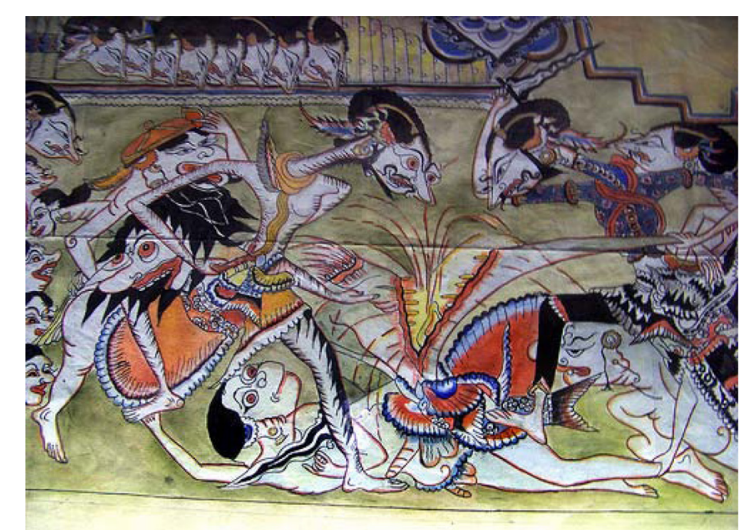

Duplikasi Wayang Beber Remeng Mangunjaya Gunungkidul

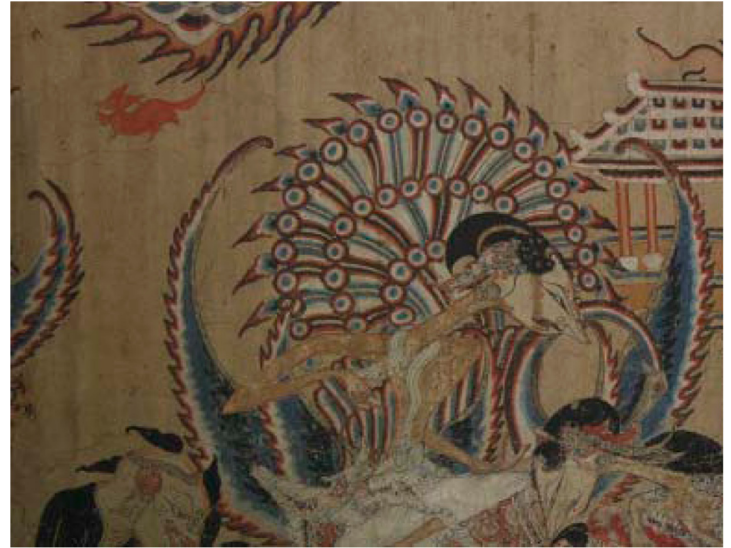

Duplikasi Wayang Beber Remeng Mangunjaya Gunungkidul

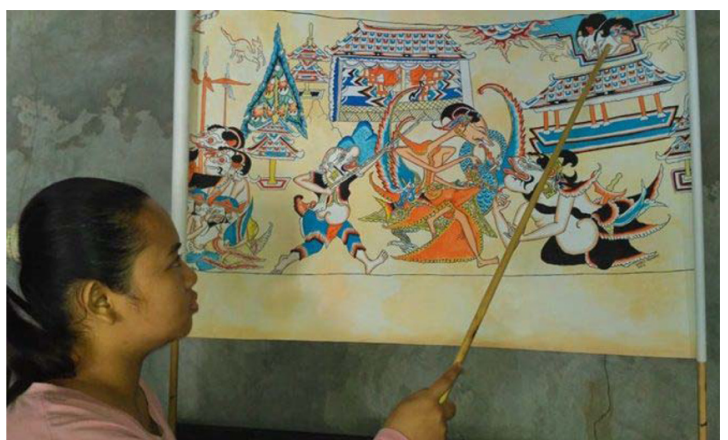

Anak perempuan pewaris Wayang Beber Gunungkidul sedang latihan mendalang 